\title{
Cost-effectiveness Analysis of the Daily HIV Pre-Exposure Prophylaxis in Men who Have Sex with Men in Barcelona
}

Francesc López Seguí ${ }^{123}$ \$, Unai Oyón Lerga ${ }^{2}$, Laura Laguna Marmol ${ }^{1}$, Pep Coll ${ }^{34}$, Angels Andreu ${ }^{1}$, Michael Meulbroek ${ }^{5}$, Guillem López Casasnovas ${ }^{2}$, Oriol Estrada Cuxart ${ }^{1}$, Jordi Ara Rey ${ }^{1}$, Carles Quiñones ${ }^{1}$, Fèlix Pérez ${ }^{5}$, Javier Fernandez ${ }^{5}$, Àngel Rivero ${ }^{5}$, Bonaventura Clotet ${ }^{34}$

${ }^{1}$ Hospital Germans Trias i Pujol

${ }^{2}$ Centre de Recerca en Economia de la Salut

${ }^{3}$ Fundació Lluita contra la SIDA

${ }^{4}$ AIDS Research Institute-IrsiCaixa

${ }^{5}$ P Projecte dels NOMS-Hispanosida

$\S$ Corresponding author: Francesc López Seguí

Carretera de Canyet, s/n

Badalona, 08916, Spain

Phone: 0034634283698

Email: flopezse.germanstrias@gencat.cat

E-mail addresses of authors:

FL: francesc.lopez@cmail.cat

UO: unaioyon99@gmail.com

LL: 1lagunam.germanstrias@gencat.cat

PC: pcoll@flsida.org

AA: aandreu.germanstrias@gencat.cat

MM: mmeulbroek@hispanosida.com

GL: guillem.lopez@upf.edu

OE: innovacio.mn.ics@gencat.cat

JA: gterritorial.mn.ics@gencat.cat

CQ: cquinonesr.germanstrias@gencat.cat

FP: fperez@bcncheckpoint.com

JF: jfernandez@bcncheckpoint.com

AR: arivero@bcncheckpoint.com

BC: bclotet@irsicaixa.es

Keywords: Preexposure prophylaxis, transmission model, PrEP, economic evaluation, HIV, economic evaluation, health economics.

Word count: Abstract: 216/350; Main text: 3226/3500 


\begin{abstract}
Introduction: Pre-Exposure Prophylaxis (PrEP) for HIV prevention has been implemented in several countries. Previous literature has shown that its cost-effectiveness (and, under some specifications, cost-saving character) is dependent on the reduction in price due to generics, the time-horizon and its effectiveness. The intervention has never been studied in Catalonia, a territory with extensive implementation.
\end{abstract}

Methods: Economic evaluation of the implementation of HIV pre-exposition prophylaxis using administrative data from Men who have Sex with Men (MSM) who receive the treatment (at the generic price). A deterministic compartmental model and a social perspective with a microcosting approach over the time horizon 2022-2062 are used. A baseline $86 \%$ effectiveness of PrEP is assumed.

Results: Daily oral PrEP is found to be cost-saving: discounted savings in costs are attained after 16 years, and after 40 years they reach 81 million euros. In terms of health indicators, 10,322 additional discounted QALYs are generated by the intervention. Results are sensitive to sexual behavioral patterns among MSM, the price of PrEP (reduced if offered on-demand), its effectiveness and the discount rate.

Conclusions: The use and promotion of PrEP in Catalonia is predicted to result in substantial health and monetary benefits because of reductions in HIV infections. Short-term investments in the promotion of PrEP will result in important cost-savings in the long term. 


\section{Introduction}

Human Immunodeficiency Virus (HIV) is an important disease throughout the world. Having caused and still causing large human losses $-690,000$ deaths as a result of Acquired Immunodeficiency Syndrome (AIDS) in 2019 throughout the world [UNAIDS 2021]-, and in spite of a significant reduction in new HIV infection diagnoses reported globally, it continues to affect severely populations at risk. A demographic dissection of affected citizens depicts a strong incidence in certain population sectors: notably, Men who have Sex with Men (MSM), who have increased their share in new infections over time. In 2019, MSM accounted for 57\% of total diagnoses (66\% among men) in Spain [1,2].

In this light, the use of the Pre-Exposure Prophylaxis (PrEP) for HIV prevention has been implemented in several countries. PrEP consists of antiretroviral (ARV) medication based on Tenofovir Disoproxil Fumarate and emtricitabine (TDF/FTC), taken by HIV-negative people in order to avoid HIV infection. 86 countries have put in place different programs to introduce it, with large heterogeneity in terms of coverage and target populations. The PrEPWatch initiative, powered by the AIDS Vaccine Advocacy Coalition, gathers up-to-date information on the regime, the degree of utilization, the eligibility criteria, the status of the drug (branded or generic) and the research programs conducted in the aforementioned countries [3]. Close to 5,000 patients were receiving PrEP in Spain in eight autonomous communities and one autonomous city, of which 2,400 were based in Catalonia [4].

Previous literature, with diverse environments of application and using different methodologies, has shown that the cost-effectiveness (and, under some specifications, costsaving character) of PrEP is largely dependent on the reduction in price due to generics, the time-horizon and its effectiveness. A study performed in the Netherlands finds that PrEP is cost-effective, showing significant differences in the result according to the kind of regime (ICER: 11,000€ per QALY gained for daily PrEP; 2,000€ for on-demand) [5]. Another study performed in Germany shows that PrEP is cost-saving after 11-15 years (assuming a 85\% effectiveness and performing a sensibility analysis for price reduction between $10 \%$ and $60 \%$ of branded ARV/PrEP drugs) [6]. In the UK, research has shown that $80 \%$ of the simulations attained cost-effectiveness over a lifetime horizon [7]. Conducting a prospective study, evidence from France and Canada shows that the yearly costs accrued from avoiding one infection are $75,258 €$ with no price reduction, 39,970€ with generic TDF/FTC [8]. Also performed in the Netherlands, the most recently reviewed study shows that $92 \%$ and $73 \%$ of the simulations were cost-effective, of which $52 \%$ and $23 \%$ were cost-saving (respectively, without and with risk compensation) [9].

Although all this evidence suggests scenarios in which the intervention can be cost-effective, the case has never been studied in Catalonia, a territory with extensive implementation of PrEP. In this context, using a deterministic compartmental model, this study aims to provide an economic evaluation of the introduction of daily PrEP for MSM in BCN Checkpoint (a community-based centre for the detection of HIV and other sexually transmitted infections located in Barcelona) alongside the Hospital Universitari Germans Trias i Pujol (HUGTIP), in which a large share of the total PrEP-treated people is monitored [10]. 


\section{Methods}

\section{Model}

The epidemiological model used is a deterministic compartmental model inspired by Nichols et al. (2016) and Van de Vijver et al. (2019) [5,6]. Three main groups are defined in the population: people who take PrEP and people who do not, and individuals infected, diagnosed and treated with ARV. Within the first two groups, an individual can either be infected and undiagnosed, or susceptible to be infected. Once an individual gets infected, the disease status is divided in nine infection stages (Annex 1). Within the group of susceptible people, a subdivision in two groups is done according to the level of sexual activity. Only people in the most sexually active group (more than 10 different sexual partners a year) qualify to be administered PrEP through the public health system, as it is assumed that they do fulfill at least one of the other conditions (Annex 2).

The model is fully identified by a group of differential equations (Annex 3) which calculate the number of susceptible individuals with and without PrEP, the number of infected, undiagnosed individuals with and without PrEP, and the number of treated individuals. The time horizon is chosen to be 40 years, as this is the remaining life expectancy at the average age of diagnosis of HIV. A baseline $86 \%$ effectiveness of PrEP is assumed.

Finally, in order to construct the cost-effectiveness analysis, each compartment is assigned a cost and Quality-Adjusted Life Years (QALYs). These indicators adjust remaining life years to account for morbidities (Annex 4). Costs and QALYs are discounted at a 3\% yearly rate at baseline. A counterfactual in which PrEP is not put in place is constructed, and the relevant indicators are constructed from a comparison between both scenarios.

\section{Costs}

A micro-costing through a social perspective approach has been adopted. The unit costs and the degree of utilization of each component in annual PrEP and ARV treatments have been retrieved from current treatment data from the hospital pharmacy service of HUGTIP, at the laboratory prices financed by the Catalan Health Service, the organism in charge of contracting health services. The costs of PrEP are borne fully by the National Health System (NHS), which provides them free of charge through the hospital pharmacy services or authorized care centres. The global, itemized annual costs of PrEP and the HIV treatment for an HIV-infected person (drugs administered and the complete medical monitoring provided alongside) are shown in the Annex (Annex 5).

For a person receiving PrEP, a first visit to a specialized practitioner (76.60€) and three subsequent visits (to initiate the treatment and for the follow-up, scheduled quarterly) for a global amount of $165.03 €$, are organized. HIV serologies, alongside blood and urine test, are done quarterly (28.76€ and 493.12€, respectively), and basal and quarterly tests for STI 
detection (syphilis, gonorrhoea and chlamydia), summing up to $341.52 €$. Finally, basal hepatitis A and B serologies, as well as a yearly hepatitis C serology (costs included in the initial visit). Close to one fourth of the yearly costs of PrEP accrue from the TFD/FTC tablets ( $28 €$ monthly, at the generic price, for a global amount of $336 €$ ). The monitoring of PrEP is done quarterly. All in all, the global annual costs for a typical individual in the first year of a daily PrEP regime in Catalonia add up to $1,433.84 €$. This quantity reflects the prescribed and expected usage of the public medical services in the absence of any adverse event.

Alternatively, a HIV-infected individual may enter treatment for an average yearly value of $8,534 €$ during his first year. Subsequent years imply a total cost of 7,451.42€. Two initial visits (one with the specialized practitioner, one with the hospital pharmacy service) are scheduled (153.20€), as well as 4 quarterly visits for a global amount of 220.04€. A confirmatory HIV test and Hepatitis C, HAV, HBV, syphilis and toxoplasma serologies are included in the costs of the initial visits. Two initial clinical analysis (first visit clinical test, and STIs clinical test, $238.16 €$ ), five subsequent analyses (396€), a CD4/CD8 test per visit (147.50€), a yearly syphilis serology (6.62€), and a basal HIV genotyping (340€), conform the rest of the costs. Eventually, the monthly ARV drugs, which add up to 7,032€ (586€ per month, at the price agreed by the Catalan Health Services, SCS) constitute $82.39 \%$ of the global costs.

In order to enrich the analysis and expand the perspective of the economic evaluation, the introduction of social costs into the model is considered. Work absences and transport costs to receive treatment will be included by assuming 4 hours of waiting times per outpatient visit to the medical centre [11]. Consequently, the average number of visits times the hours spent there, times the average labour costs in Catalonia, times the number of people in the relevant treatment, times the employment rate, gives the global cost of work absence per period.

All data refer to 2019. Ethical approval and consent were not required.

\section{Results}

Under baseline specifications, the implementation of PrEP is found to be cost-saving (and thus, cost-effective) for the relevant time horizon of 40 years. Savings in costs are realized after 166 months (13.83 years) of implementation, 196 months if costs are discounted at a 3\% rate yearly (16.33 years). After 40 years of PrEP scale-up, 81,032,564€ are saved globally, out of which $93,782,731 €$ are saved from the healthcare payer perspective, and 12,750,167€ are additional costs borne by the patients, who incur losses from work absences and transport costs. It is essential to note the duality in cost dynamics: the intervention is cost-saving globally and for the public health system, but generates extra social costs as a result of the continuous medical monitoring of PrEP, which implies more outpatient visits than the counterfactual.

Furthermore, 23,372 additional QALYs (10,322 discounted annually at 3\%) are obtained by using PrEP as a prevention mechanism. No ICER is computed because PrEP generates sizable health benefits at a lower cost than the counterfactual. Figure 1 gathers the evolution of people 
on PrEP, and ARV therapy in both scenarios, illustrating that introducing PrEP, ceteris paribus, implies fewer people on ARV from the third year of implementation because of averted infections.

With respect to costs, ARV drugs for an HIV-infected MSM oscillate over 79-80\% of global costs $(81-82 \%$ of healthcare costs), while PrEP costs oscillate over $1.6 \%$ (1.7-1.9\% of healthcare costs). It is important to recall the centrality of complementary testing and medical monitoring alongside the daily intake of TDF/FTC, which correspond to a significant share of global costs (for both individuals on PrEP and HIV-infected with antiretroviral therapy) (Annex 6).

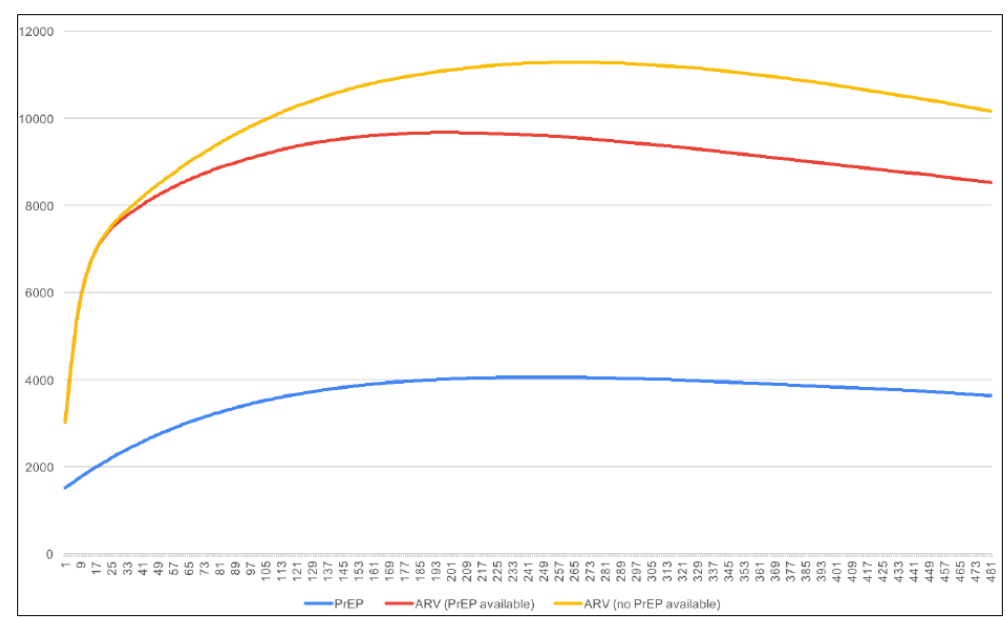

Figure 1. People on PREP and ARV, 2022-2062. Monthly evolution of the number of people on PrEP (blue), and ARV therapy in both scenarios (with PrEP, in red; without PrEP, in yellow).

\section{Sensitivity analysis}

The conclusions are especially sensitive to the discount rate (range 1.5\%-4.5\% yearly), which respectively modify discounted additional QALYs and savings in costs by $48.77 \%$ and $53.28 \%$, and $-31.43 \%$ and $-35 \%$. In either case, the intervention remains cost-saving for the whole range, between 188 and 206 months of initial implementation.

Changing one or more utility weights for QALYs in each compartment does not generate significant changes in discounted additional QALYs (8,024-11,522; baseline 10,322), except for the case of ARV-treated. Infections averted by PrEP imply systematically lower people on antiretroviral therapy, thus generating substantial health gains as measured by QALYs when the utility weight goes down to 0.45 (23,300, a $126 \%$ increase). Cost-savings materialize at the same moment as baseline.

When accounting for different demographic estimations, no significant change is appreciated in terms of QALYs, savings in costs or time to attain these savings. However, a recalibration in terms of sexual patterns strongly impacts health and monetary indicators: 14,020 additional discounted QALYs, 99.2 discounted million euros in total savings (which start in the 18th 
year), of which 116.2 million euros are saved by the healthcare payer, and 16.9 million of extra costs accrue to society in the form of work absences and transport costs.

Pivoting over the effectiveness of PrEP (40\%-98\%-100\%), against the $86 \%$ in baseline, significantly affects savings in costs. Additional discounted QALYs variation with respect to baseline range from $-63.77 \%$ to $25.55 \%$. Under the unrealistic specification of $40 \%$, PrEP is not cost-saving, and yields an ICER of 10,321€/QALY. On the one hand, given the current structure of PrEP and medical monitoring, such a low effectiveness is not realistic. On the other hand, individual effectiveness for fully-adherent patients is close to $100 \%$, so the complete effectiveness may be feasible for a sufficient degree of compromise in the daily intake, thus saving 136.6 million euros and generating 12,959 QALYs (with respect to the counterfactual, not with the PrEP scenario under baseline specifications). However, the marginal impact from assuming effectiveness to be $100 \%$ with respect to the $98 \%$ specification is negative in savings: the marginally averted infections (and costs in ARV) do not compensate for the additional costs of keeping everybody in PrEP once they starts).

Finally, a reduction in price of 50\% following the approval of an on-demand PrEP regime, as assumed in other studies [Nichols et al., 2016; Reitsema et al., 2020], does not affect health outcomes, but generates healthcare savings of 152.4 million euros, which start to accrue as soon as 8 years and 8 months after deployment. The results obtained can be extrapolated to an increased-effectiveness scenario (98\%), thus resulting in a total cumulative saving of 218 million euros.

\section{Discussion}

The number of people undergoing PrEP in the Catalan population is 2,400, constituting approximately half of all patients treated in Spain. Applying the same deterministic compartmental mathematical model used by Nichols et al. and Van de Vijver et al., and in line with other studies, favourable cost-effectiveness results have been obtained, that estimate a saving of 93.8 million over a 40-year horizon for a daily regimen and considering, for a conservative scenario, an effectiveness of $86 \%$ taken as a reference from other studies [5-9].

It is worth highlighting the weight of the direct costs of the drugs on the result (above $70 \%$ across the time horizon scanned). Thus, the cost savings are due in part to the start of PrEP in Spain, in November 2019, using the generic presentation of the drugs, which made the global annual cost of PrEP in Spain for a person during the first year of treatment to significantly decrease to $€ 1,433.84$. With no adjustment, the difference in PrEP costs between the available literature in other countries and this study varies between $€-600.93$ (generic presentation and daily administration regimen) [6] and $€ 5,966.16$ (daily regimen, commercial presentation) $[5,9]$. Even when the heterogeneity in PrEP administration is accounted for, the difference in prices is still relevant for the available literature. The underlying reasons can be due to the divergent prices for the drugs, but also on the national guidelines of medical monitoring and clinical testing. 
It should be noted that long-term cost savings will depend on several factors. On the one hand, the evolution of the HIV incidence curve must be analysed. Catalonia has followed a decreasing trend in new diagnoses since 2010, with a reduction in the global incidence rate from 11 to 6.1 cases per 100,000 people in 2019 [12]. Although in our model the infection rate is corrected for the change observed in recent years, if the curve further decreases in the years following the study, the cost-effectiveness results obtained could be altered. Another factor to be considered are the new therapeutic alternatives (new drugs and presentations), which once marketed could affect both the effectiveness of the treatment and its cost.

This model has three main strengths. First of all, it enables the dynamic resolution of the model from the current observational data in the relevant setting, thus making its real-world applicability an essential trait. Then, it permits a long-term, prospective economic evaluation of the impact of PrEP. Accounting for any relevant change in the epidemic, the costs, the treatments or an exogenous shock is easy within this framework, by creating a break in the parameters after the relevant time point. Finally, the administration of PrEP in this model is consistent with the extent to which it has been scaled-up in Catalonia: the national eligibility criteria are respected, and the constraint imposed by limited financial and real resources is shown by a limited take-up rate for eligible people. Furthermore, this methodology is in accordance with relevant contributions in the European literature, as aforementioned, in countries in which the HIV/AIDS epidemic is concentrated among MSM.

Several limitations are to be identified and tackled in future research. The model does not include stochastic, individual or behavioral features, losing some nuances in sexual patterns and thus transmission patterns. Besides, it does not account for risk-compensation: the introduction of PrEP may encourage sexual behaviours with higher risk by some individuals (lower condom usage rates, for instance), increasing comorbidity through secondary STIs and thus increasing the overall social and healthcare costs of the intervention, although some studies show no significant increase on STI incidence [13]. Finally, the different endogenous changes in infectivity and force of infection as a result of the evolution of the simulation and the count at different stages of the epidemic are not taken into account. Past local data on incidence and prevalence rates slightly diminish this problem. Besides, the geographic scope of the study limits the impact of this problem, since sexual encounters with people who are not included in the count of the model are highly probable: it is not a fully closed sample, so adjusting for the force of infection at different levels of sexual activity does not imply a significant departure from baseline. Nonetheless, these concerns do not imply a significant bias or inconsistency in the results. Secondary bacterial STIs are cheaply treated with generic antibiotics, so no significant budget effect should be expected. Infection with hepatitis $C$ virus could be more problematic because of the cost of the treatment, but yearly serologies included in the PrEP regime may limit the impact of its transmission.

Eventually, another caveat may jeopardize the analytical effort presented here: the distortions created by the COVID-19 in terms of mortality, reduced medical coverage and diagnoses $[14,15]$ and reduced sexual interactions because of the lockdown in Catalonia. This problem 
could be tackled by accounting for these shocks in terms of the calibration of the parameters of the model, but since this simulation starts prospectively from 2022, when the vaccination coverage in Spain will be significant and the stringency of measures very limited, no modification will be implemented. Also, there is no evidence of a correlation between incidence in SARS-CoV-19 and HIV, although some references indicate that the infection with the aforesaid coronavirus may result in more severe symptomatology for HIV-infected people [16].

Frictions in these costs arising as a consequence of such contingencies were not considered in the analysis, as they are largely dependent on behavioral unobservable and unpredictable events. Besides, if more granular microdata were readily available, transport costs could be associated with direct costs internal to the patients, as well as with traffic and environmental externalities for society. HUGTIP is not an urban hospital, so these costs could be important to the analysis. Further research could expand the ideas hereby presented.

\section{Conclusions}

Daily oral HIV pre-exposition prophylaxis targeted at-risk MSM at BCN Checkpoint and the Hospital Universitari Germans Trias i Pujol currently covers around 2,400 people. Under its current specifications in Spain and Catalonia, this study has provided a cost-effectiveness evaluation of the introduction of this prevention mechanism. Through a deterministic compartmental model calibrated to the Catalan situation, with both administrative and publiclyavailable data, the implementation of PrEP is found to be cost-saving in 16 years and 4 months, for a 40-years horizon, freeing 93.8 million euros from the healthcare payer perspective by averting infections, but generating an extra burden of 12.75 million for the society as a whole through work absences and transport costs. In terms of health indicators, 10,322 additional discounted QALYs are generated by the intervention. Global health results (discounted QALYs) are sensitive to sexual behavioral patterns among MSM, the discount rate and the utility perceived by people on antiretroviral therapy. The time needed to attain savings in costs and its magnitude are largely dependent on the price of PrEP (reduced if offered on-demand), its effectiveness, the discount rate and sexual behaviour. 


\section{Competing interests}

AA reports advisory board membership and speakers' fees from Gilead, Janssen-Cilag, MSD, ViiV and Pfizer.

PC reports grants from Gilead Sciences; and fees from Janssen Pharmaceuticals, Merck, Gilead Sciences and ViiV Healthcare for serving on their scientific advisory boards

\section{Authors' contributions}

Conceptualization, FL, LL, AA, PC; methodology, FL, UO; software, UO; validation, FL, BC, PC; formal analysis, UO, FL; investigation, FL, LL, AA, PC, UO; resources, FL, PC; data curation, UO, LL, AA; writing — original draft preparation, UO, FL; writing-review and editing, FL, LL, AA, PC, GL, OE, JA, CQ, BC, MM, FP, JF, AR; visualization, FL, UO; supervision, FL, BC; project administration, FL; funding acquisition, BC, PC, CQ. All authors have read and agreed to the published version of the manuscript.

\section{Acknowledgements}

Advice given by Brooke Nichols (School of Public Health, Boston University) has been a great help in the methodology definition of the study.

Special thanks are extended to the staff of BCN Checkpoint.

Funding: This research received no specific grant from any funding agency 


\section{References}

1. UNAIDS, 2021. AIDSInfo Data on HIV. (2021, April). https://aidsinfo.unaids.org/.

2. UNAIDS, 2019. AIDSInfo National HIV Indicators for General Population and MSM in Spain. https://www.unaids.org/en/regionscountries/countries/spain.

3. PrEPWatch.org, 2021. PrEPWatch Country Updates, Q1 2021. (2021, April). https://www.prepwatch.org/inpractice/country-updates/.

4. Agència de Salut Pública de Catalunya (ASPCAT), 2019. La profilaxi preexposició (PrEP) al VIH ja està disponible a Catalunya https://salutpublica.gencat.cat/ca/detalls/Article/PrEP

5. Nichols, B. E., Boucher, C., van der Valk, M., Rijnders, B., \& Van de Vijver, D. (2016). Cost-effectiveness analysis of pre-exposure prophylaxis for HIV-1 prevention in the Netherlands: a mathematical modelling study. The Lancet Infectious diseases, 16(12), 1423-1429.

6. Van de Vijver, D. A., Richter, A.-K., Boucher, C. A., Gunsenheimer-Bartmeyer, B., Kollan, C., Nichols, B. E., Spinner, C. D., Wasem, J., Schewe, K., \& Neumann, A. (2019). Cost-effectiveness and budget effect of pre-exposure prophylaxis for HIV-1 prevention in Germany from 2018 to 2058. Eurosurveillance, 24(7).

7. Cambiano, V., Miners, A., Dunn, D., McCormack, S., Ong, K. J., Gill, O. N., Nardone, A., Desai, M., Field, N., Hart, G., Delpech, V., Cairns, G., Rodger, A., \& Phillips, A. N. (2018). Cost-effectiveness of pre-exposure prophylaxis for HIV prevention in men who have sex with men in the UK: a modelling study and health economic evaluation. The Lancet Infectious Diseases, 18(1).

8. Durand-Zaleski, I., Mutuon, P., Charreau, I., Tremblay, C., Rojas, D., Pialoux, G., Chidiac, C., Capitant, C., Spire, B., Cotte, L., Chas, J., Meyer, L., \& Molina, J. M. (2018). Costs and benefits of on-demand HIV preexposure prophylaxis in MSM. AIDS, 32(1), 95-102.

9. Reitsema, M., Hoek, A. J., van der Loeff, M. S., Hoornenborg, E., van Sighem, A., Wallinga, J., van Benthem, B., \& Xiridou, M. (2020). Preexposure prophylaxis for men who have sex with men in the Netherlands: impact on HIV and Neisseria gonorrhoeae transmission and cost-effectiveness. AIDS, 34(4), 621-630.

10. BCN Checkpoint, 2021. BCN Checkpoint - The Center. (2021, June). https://www.bcncheckpoint.com/bcncheckpoint/.

11. Ouellet, E., Durand, M., Guertin, J. R., LeLorier, J., \& Tremblay, C. L. (2015). Cost Effectiveness of 'On Demand' Hiv Pre-Exposure Prophylaxis for Non-Injection Drug-Using Men Who Have Sex with Men in Canada. Canadian Journal of Infectious Diseases and Medical Microbiology, 26(1), 23-29. https://doi.org/10.1155/2015/964512

12. Vigilància epidemiològica del VIH i la SIDA a Catalunya, Informe annual 2019

13. Iniesta, Carlos, et al. "Implementation of pre-exposure prophylaxis programme in Spain. Feasibility of four different delivery models." PloS one 16.2 (2021): e0246129.

14. Pifarré i Arolas, H.; Vidal-Alaball, J.; Gil, J.; López, F.; Nicodemo, C.; Saez, M. Missing Diagnoses during the COVID-19 Pandemic: A Year in Review. Int. J. Environ. Res. Public Health 2021, 18, 5335. https://doi.org/10.3390/ijerph18105335

15. Lopez Segui F, Hernandez Guillamet G, Pifarré Arolas H, Marin Gomez X, Ruiz Comellas A, Ramirez Morros AM, Adroher Mas C, Vidal-Alaball J. Characterization and Identification of Variations in Types of Primary Care Visits Before and During the COVID-19 Pandemic in Catalonia: Big Data Analysis Study. Journal of Medical Internet Research. 12/06/2021:29622 (forthcoming/in press) PMID: 34313600

16. Ambrosini, J., \& Blanco JL;Reyes-Urueña JM;Davies MA;Sued O;Marcos MA;Martínez E;Bertagnolio S;Alcamí J;Miro JM; ; (2021, May). Overview of SARS-CoV-2 infection in adults living with HIV. The lancet. HIV. https://pubmed.ncbi.nlm.nih.gov/33915101/. 


\section{Annex}

\section{Annex 1}

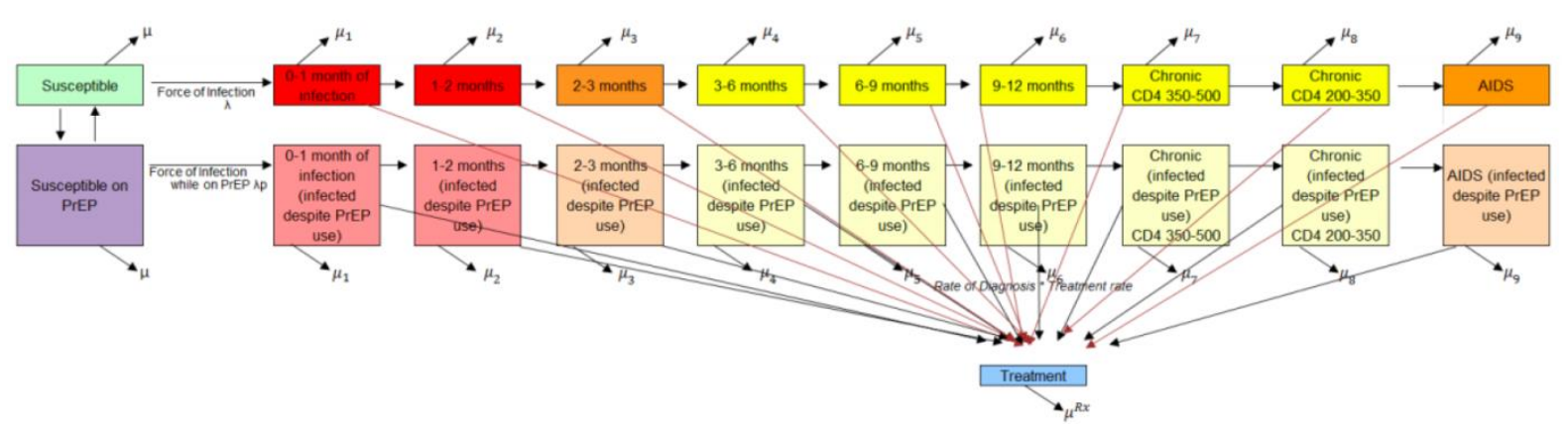

Figure 1. Deterministic compartmental mathematical model of HIV transmission.*

Source: Nichols et al. (2016) supplementary material.

*: $\mu=$ mortality general population, $\mu \mathrm{k}=$ mortality untreated HIV-infected in infection stage $\mathrm{k}$, $\mu \mathrm{Rx}=$ mortality ARV treated, $\lambda=$ force of infection, $\lambda \mathrm{P}=$ force of infection while on PrEP

Stage 1 is the first month of infection, stage 2 is the second one, stage 3 is the third one, stage 4 includes the period from the fourth to the sixth month, stage 5 includes the period from the seventh to the ninth month, stage 6 includes the period from the tenth to the twelfth month, stages 7 and 8 constitute the chronic phase, with a CD4 cell count per $\mu \mathrm{l}$ of 350-500 and 200-350, respectively, and stage 9 is the AIDS phase, with a CD4 cell count per $\mu$ l lower than 200. Finally, an individual may be infected, diagnosed and on treatment.

\section{Annex 2}

\begin{tabular}{|r|r|}
\hline $\begin{array}{r}\text { HIV-negative MSM and transgender people over 18 } \\
\text { years old } \\
\text { (at least two to be eligible) }\end{array}$ & HIV-negative female sex workers \\
\hline More than 10 sexual partners during the last year & \\
\cline { 1 - 1 } Condomless anal intercourse during the last year & \\
\cline { 1 - 1 } $\begin{array}{r}\text { Drug consumption related with condomless sexduring } \\
\text { the last year }\end{array}$ & \\
\hline Several PEP treatments during the last year & \multirow{2}{*}{ Regular condomless intercourse } \\
\hline At least one bacterial STI during the last year & \\
\hline
\end{tabular}

Table 1. PrEP eligibility criteria in Spain

Source: Spanish Ministry of Health 


\section{Annex 3}

$$
\begin{aligned}
& S_{i, t}=S_{i, t-1}\left(1+\phi_{t}-\mu-\lambda_{i, t}-\omega_{i}\right)+S_{i, t-1}^{P}\left(\omega_{o f f}\right) \\
& S_{t}^{P}=S_{t-1}^{P}\left(1+\phi_{t}-\mu-\lambda_{2 P, t}-\omega_{\text {off }}\right)+S_{2, t-1}\left(\omega_{2}\right) \\
& I_{1, t}^{l}=\sum_{i=1}^{2} S_{i, t-1}\left(\lambda_{i, j}\right)-I_{1, t-1}^{I}\left(-1+\gamma_{1}+\mu_{1}+\tau_{1} \varrho R X\right) \\
& I_{1, t}^{P}=S_{t-1}^{P}\left(\lambda_{2 P}\right)-I_{1, t-1}^{P}\left(-1+\gamma_{1}+\mu_{1}+\tau_{1}^{P} \varrho R X\right) \\
& I_{k, t}^{I}=I_{k-1, t-1}^{I}\left(\gamma_{k-1}\right)-I_{k, t-1}^{I}\left(-1+\gamma_{k}+\mu_{k}+\tau_{k} \mathrm{\varrho} R X\right) \\
& I_{k, t}^{P}=I_{k-1, t-1}^{P}\left(\gamma_{k-1}\right)-I_{k, t-1}^{P}\left(-1+\gamma_{k}+\mu_{k}+\tau_{k}^{p} \mathrm{Q} R X\right) \\
& \left.\left.I_{t}^{R X}=\sum_{k=1}^{9}{ }^{I} I_{k, t-1}^{I}\left(\tau_{k} \mathrm{Q} R X\right)\right]+\sum_{k=1}^{9}{ }_{k, t-1}^{P}\left(\tau_{k}^{p} \mathrm{Q} R X\right)\right]+I_{t-1}^{R X}\left(1-\mu_{R X}\right)
\end{aligned}
$$

\begin{tabular}{|c|c|c|c|}
\hline Parameter & $\operatorname{Value}(s) * 1 * 2$ & Source & Meaning \\
\hline$\gamma_{k}$ & $\begin{array}{l}.992 ; .978 ; .981 ; .309 ; .312 ; \\
.312 ; .335 ; .269 ; 0\end{array}$ & Residual; Nichols (2016) & Rate of stage k progression \\
\hline$\phi$ & .00064 & INE (2019) & Raw population growth \\
\hline$\mu, \mu_{k}, \mu_{R X}$ & $\begin{array}{l}.0007(\text { general; } k=1-6) \\
.00113(k=7,8) ; \\
.00624(k=9) ; .00182(\mathrm{RX})\end{array}$ & $\begin{array}{l}\text { INE (2019); Nagakawa et } \\
\text { al. (2012) }\end{array}$ & $\begin{array}{l}\text { General mortality; mortality } \\
\text { at stage } \mathrm{k} \text {; mortality on ARV }\end{array}$ \\
\hline $\begin{array}{l}\lambda_{i}, \lambda_{2 P} \text { at } \\
t=0-12\end{array}$ & $\begin{array}{l}.00049 ; .00534 ; .00075 \\
\text { then decrease at a rate } \\
7.483 \% / \text { year until } t=120\end{array}$ & $\begin{array}{l}\text { HUGTIP; Fundació Lluita } \\
\text { contra la Sida; Durand et } \\
\text { al. (2018) }\end{array}$ & $\begin{array}{l}\text { Incidence rate for } i \text { and } i=2 \\
\text { with PrEP }\end{array}$ \\
\hline$\omega_{i}, \omega_{o f f}$ & $0(i=1) ; .00406(i=2) ; 0$ & $\begin{array}{l}\text { HUGTIP; Fundació Lluita } \\
\text { contra la Sida }\end{array}$ & $\begin{array}{l}\text { Rate to enter PrEP for } i \text {; rate } \\
\text { to discontinue PrEP }\end{array}$ \\
\hline$\rho$ & 1 & Assumed & Rate of tested derived to care \\
\hline$\tau_{k}, \tau_{k}^{P}$ & $\begin{array}{l}.0069 ; .021 ; .018 ; .024 \\
.021 ; .021 ; . .064 ; .042 ; .74 \\
0 ; 0 ; 1 ; 0 ; 0 ; 0 ; 0 ; 0 ; 0\end{array}$ & $\begin{array}{l}\text { Nichols et al. (2016); } \\
\text { HUGTIP; Fundació Lluita } \\
\text { contra la Sida }\end{array}$ & Testing rate at stage $k$ \\
\hline$R X$ & 1 & Assumed & Rate of treated once in care \\
\hline
\end{tabular}

where SP and Si for $i=1,2$ stand for the number of susceptible individuals with and without PrEP, IP $k$ and II $k$ for $k=1 . ., 9$ stand for the number of infected, undiagnosed individuals with and without PrEP, and IRX stands for the number of treated individuals.

Table 2. Description and calibration of the monthly baseline parameters of the model. 


\section{Annex 4}

\begin{tabular}{|l|c|c|c|c|}
\hline Compartment & $\begin{array}{c}\text { Utility } \\
\text { weight, } \\
\text { baseline }\end{array}$ & Source & $\begin{array}{c}\text { Utility } \\
\text { weights for } \\
\text { sensitivity } \\
\text { analysis }\end{array}$ & Source \\
\hline Susceptible/On PrEP & 1 & Assumed* & $0.94-1$ & Assumed \\
\hline CD4 cell count $>350 / \mu l$ & 0.94 & Tengs et al. (2002) & $0.87-1$ & $\begin{array}{c}\text { Honiden et al. (2006), } \\
\text { Sanders et al. (2005) }\end{array}$ \\
\hline $\begin{array}{l}\text { CD4 cell count 200- } \\
\text { 350/ } \mu l\end{array}$ & 0.82 & Tengs et al. (2002) & $0.45-1$ & $\begin{array}{l}\text { Honiden et al. (2006), } \\
\text { Sanders et al. (2005) }\end{array}$ \\
\hline AIDS stage & 0.70 & Tengs et al. (2002) & $0.24-0.8$ & $\begin{array}{l}\text { Sanders et al. (2005), } \\
\text { Tengs et al. (2002), } \\
\text { Tsevat et al. (1999) }\end{array}$ \\
\hline Infected on treatment & 0.94 & Tengs et al. (2002) & $0.45-1$ & $\begin{array}{l}\text { Honiden et al. (2006), } \\
\text { Sanders et al. (2005), } \\
\text { Tengs et al. (2002), } \\
\text { Tsevat et al. (1999) }\end{array}$ \\
\hline
\end{tabular}

Table 3. Compartmental utility weights. *: No significant side effects reported from PrEP. Source: Cited individually.

Annex 5

\begin{tabular}{|c|c|c|c|c|c|c|c|}
\hline Item & Base & Beginning & $\begin{array}{l}\text { Monitoring } \\
1\end{array}$ & $\begin{array}{l}\text { Monitoring } \\
2\end{array}$ & Total & $\begin{array}{l}\text { Unit } \\
\text { costs }\end{array}$ & $\begin{array}{l}\text { Total } \\
\text { costs }\end{array}$ \\
\hline First Visit with Specialized Practitioner & 1 & & & & 1 & 76.60 & 76.60 \\
\hline $\begin{array}{l}\text { Subsequent Visits with Specialized } \\
\text { Practitioner }\end{array}$ & & 1 & 1 & 1 & 3 & 55.01 & 165.03 \\
\hline Clinical test - without CD4 count & 1 & 1 & 1 & 1 & 4 & 123.28 & 493.12 \\
\hline HIV Serology & & 1 & 1 & 1 & 3 & 7.19 & 21.57 \\
\hline $\begin{array}{l}\text { STIs Tests (Syphilis, Gonorrhea, } \\
\text { Chlamydia) }\end{array}$ & 1 & 1 & 1 & 1 & 4 & 85.38 & 341.52 \\
\hline PrEP Drugs & 3 & 3 & 3 & 3 & 12 & 28 & 336 \\
\hline YEARLY TOTAL & & & & & & & $1,433.84$ \\
\hline
\end{tabular}

Table 4.1. Yearly PrEP costs for the initial year, in 2021 euros as financed by the SCS. Source: HUGTIP hospital pharmacy and Pep Coll, personal communication. 


\begin{tabular}{|c|c|c|c|c|c|c|c|}
\hline Item & Base & Beginning & Monitoring 1 & Monitoring 2 & Total & $\begin{array}{l}\text { Unit } \\
\text { costs }\end{array}$ & $\begin{array}{l}\text { Total } \\
\text { costs }\end{array}$ \\
\hline $\begin{array}{l}\text { Subsequent Visits with Specialized } \\
\text { Practitioner }\end{array}$ & 1 & 1 & 1 & 1 & 4 & 55.01 & 220.04 \\
\hline Clinical test - without CD4 count & 1 & 1 & 1 & 1 & 4 & 123.28 & 493.12 \\
\hline HIV Serology & 1 & 1 & 1 & 1 & 4 & 7.19 & 28.76 \\
\hline $\begin{array}{l}\text { STIs Tests (Syphilis, Gonorrhea, } \\
\text { Chlamydia) }\end{array}$ & 1 & 1 & 1 & 1 & 4 & 85.38 & 341.52 \\
\hline PrEP Drugs & 3 & 3 & 3 & 3 & 12 & 28 & 336 \\
\hline \multicolumn{7}{|l|}{ YEARLY TOTAL } & 1,419 \\
\hline
\end{tabular}

Table 4.2. Yearly PrEP costs for $t>12$, in 2021 euros as financed by the SCS.

Source: HUGTIP hospital pharmacy and Pep Coll, personal communication.

\begin{tabular}{|c|c|c|c|c|c|c|c|c|c|c|c|c|c|c|c|}
\hline Item & Base & M2 & M3 & M4 & M5 & M6 & M7 & M8 & M9 & $\begin{array}{l}\text { M } \\
10\end{array}$ & $\begin{array}{l}\mathbf{M} \\
\mathbf{1 1}\end{array}$ & $\begin{array}{l}\text { M } \\
\mathbf{1 2}\end{array}$ & Total & $\begin{array}{l}\text { Unit } \\
\text { costs }\end{array}$ & $\begin{array}{l}\text { Total } \\
\text { costs }\end{array}$ \\
\hline $\begin{array}{l}\text { First Visit to the } \\
\text { Hospital } \\
\text { Pharmacy }\end{array}$ & 1 & & & & & & & & & & & & 1 & 76.60 & 76.60 \\
\hline $\begin{array}{l}\text { First Visit to the } \\
\text { Specialized } \\
\text { Practitioner }\end{array}$ & 1 & & & & & & & & & & & & 1 & 76.60 & 76.60 \\
\hline $\begin{array}{l}\text { Subsequent } \\
\text { Visits with } \\
\text { Specialized } \\
\text { Practitioner }\end{array}$ & & & 1 & & & 1 & & & 1 & & & 1 & 4 & 55.01 & 220.04 \\
\hline CD4/CD8 tests & 1 & & 1 & & & 1 & & & 1 & & & 1 & 5 & 29.50 & 147.50 \\
\hline $\begin{array}{l}\text { First visit } \\
\text { clinical analyses }\end{array}$ & 1 & & & & & & & & & & & & & 152.78 & 152.78 \\
\hline $\begin{array}{l}\text { Subsequent } \\
\text { visits clinical } \\
\text { analyses }\end{array}$ & & 1 & 1 & & & 1 & & & 1 & & & 1 & 5 & 79.20 & 396 \\
\hline STIs Tests & 1 & & & & & & & & & & & & 1 & 85.38 & 85.38 \\
\hline $\begin{array}{l}\text { Syphilis } \\
\text { Serology }\end{array}$ & & & & & & & & & & & & 1 & 1 & 6.62 & 6.62 \\
\hline $\begin{array}{l}\text { ARV } \\
\text { Medication }\end{array}$ & 1 & 1 & 1 & 1 & 1 & 1 & 1 & 1 & 1 & 1 & 1 & 1 & 12 & 586 & 7,032 \\
\hline \multicolumn{15}{|c|}{ YEARLY TOTAL } & 8,534 \\
\hline
\end{tabular}

Table 5.1. Yearly ARV costs for the initial year, in 2021 euros as financed by the SCS. Source: HUGTIP hospital pharmacy and Pep Coll, personal communication. 


\begin{tabular}{|c|c|c|c|c|c|c|c|c|c|c|c|c|c|c|c|}
\hline Item & Base & M2 & M3 & M4 & M5 & M6 & M7 & M8 & M9 & $\begin{array}{l}\text { M } \\
\mathbf{1 0}\end{array}$ & $\begin{array}{l}\text { M } \\
11\end{array}$ & $\begin{array}{l}\text { M } \\
12\end{array}$ & Total & $\begin{array}{l}\text { Unit } \\
\text { costs }\end{array}$ & $\begin{array}{l}\text { Total } \\
\text { costs }\end{array}$ \\
\hline $\begin{array}{l}\text { Subsequent } \\
\text { Visits with } \\
\text { Specialized } \\
\text { Practitioner }\end{array}$ & & & & & & 1 & & & & & & 1 & 2 & 55.01 & 110.02 \\
\hline $\begin{array}{l}\text { CD4/CD8 } \\
\text { tests }\end{array}$ & & & & & & 1 & & & & & & 1 & 2 & 29.50 & 59 \\
\hline $\begin{array}{l}\text { Subsequent } \\
\text { visits } \\
\text { clinical } \\
\text { analyses }\end{array}$ & & & & & & 1 & & & & & & 1 & 2 & 79.20 & 158.40 \\
\hline STIs Tests & 1 & & & & & & & & & & & & 1 & 85.38 & 85.38 \\
\hline $\begin{array}{l}\text { Syphilis } \\
\text { Serology }\end{array}$ & & & & & & & & & & & & 1 & 1 & 6.62 & 6.62 \\
\hline $\begin{array}{l}\text { ARV } \\
\text { Medication }\end{array}$ & 1 & 1 & 1 & 1 & 1 & 1 & 1 & 1 & 1 & 1 & 1 & 1 & 12 & 586 & 7,032 \\
\hline & & & & & & RI & TO & & & & & & & & $7,451.42$ \\
\hline
\end{tabular}

Table 5.2. Yearly ARV costs for $t>12$, in 2021 euros as financed by the SCS. Source: HUGTIP hospital pharmacy and Pep Coll, personal communication.

\section{Annex 6}

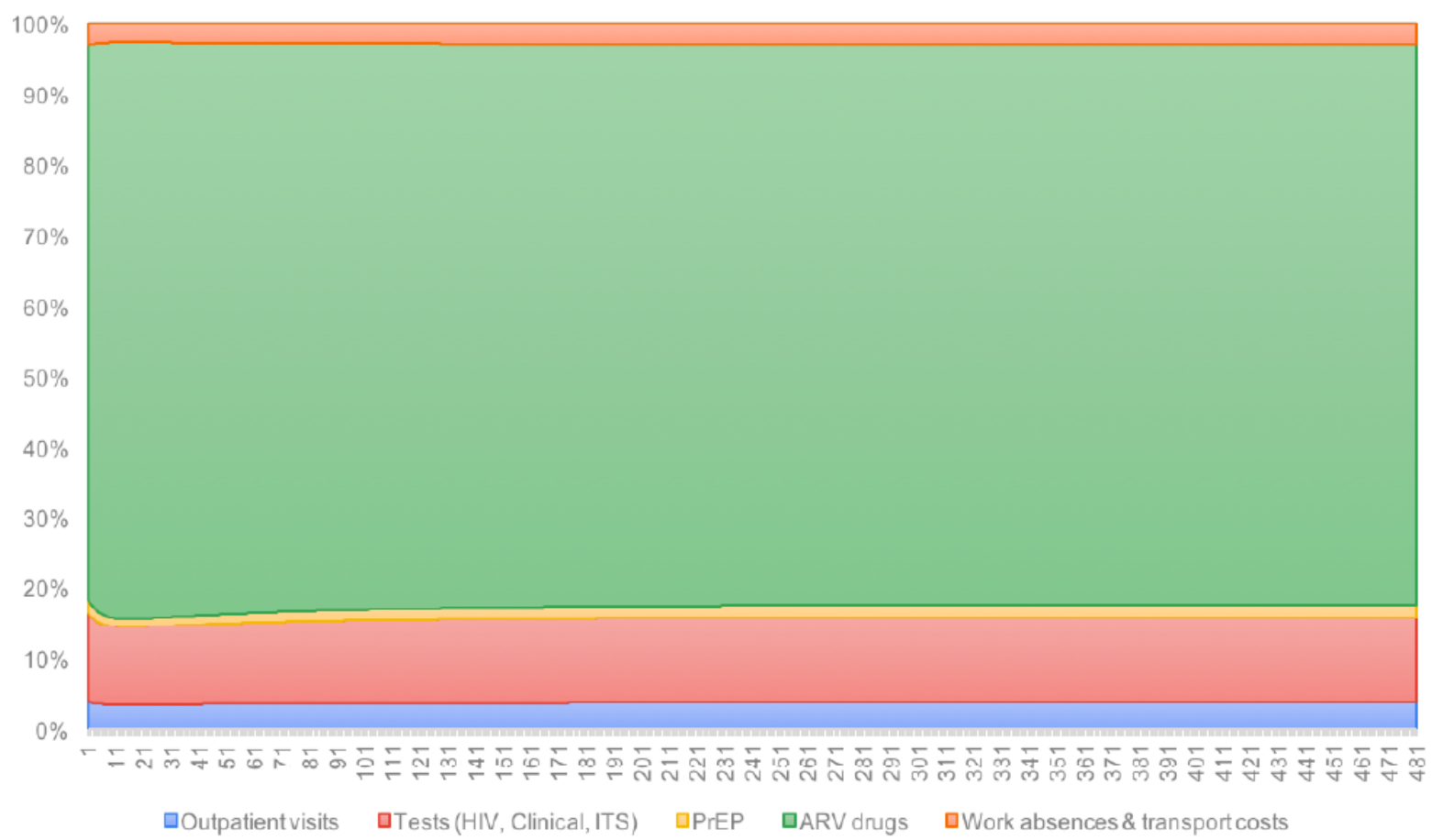

Figure 2. Share of costs per group of items over time for PrEP scenario. 